\title{
Personal relatedness and attachment in infants of mothers with borderline personality disorder
}

\author{
R. PETER HOBSON, MATTHEW PATRICK, LISA CRANDELL, \\ ROSA GARCÍA-PÉREZ, AND ANTHONY LEE \\ Tavistock Clinic, University College, London
}

\begin{abstract}
The principal aim of this study was to assess personal relatedness and attachment patterns in 12-month-old infants of mothers with borderline personality disorder (BPD). We also evaluated maternal intrusive insensitivity toward the infants in semistructured play. We videotaped 10 mother-infant dyads with borderline mothers and 22 dyads where the mothers were free from psychopathology, in three different settings: a modification of Winnicott's Set Situation in which infants faced an initially unresponsive ("still-face") stranger, who subsequently tried to engage the infant in a game of give and take; the Strange Situation of Ainsworth and Wittig; and a situation in which mothers were requested to teach their infants to play with miniature figures and a toy train. In relation to a set of a priori predictions, the results revealed significant group differences as follows: (a) compared with control infants, toward the stranger the infants of mothers with BPD showed lower levels of "availability for positive engagement," lower ratings of "behavior organization and mood state," and a lower proportion of interpersonally directed looks that were positive; (b) in the Strange Situation, a higher proportion (8 out of 10) of infants of borderline mothers were categorized as Disorganized; and (c) in play, mothers with BPD were rated as more "intrusively insensitive" toward their infants. The results are discussed in relation to hypotheses concerning the interpersonal relations of women with BPD, and possible implications for their infants' development.
\end{abstract}

The design of the present study in developmental psychopathology was motivated by two concerns. Our primary aim was to examine the hypothesis that by the end of the first year of life, infants of mothers with borderline per-

This research was generously supported by grants from the Winnicott Trust, the Hayward Foundation, and the Baily Thomas Charitable Fund, as well as by a Wellcome Fellowship to Matthew Patrick and an NIH Fellowship to Lisa Crandell. We also received support from the UK National Health R\&D Budget. We are indebted to the mothers and infants who agreed to take part, Lynne Murray for inspiration and guidance, Lucy Chiemielski and Leezah Hertzmann for their help with ratings of videotapes, Betty Carlson and Alan Sroufe for their invaluable and very generous input, and Jessica Meyer for her helpful comments and suggestions.

Address correspondence and reprint requests to: $\mathrm{R}$. Peter Hobson, Tavistock Clinic, 120 Belsize Lane, London NW35BA, UK; E-mail: r.hobson@ucl.ac.uk. sonality disorder (BPD) may be ill equipped to maintain emotional equilibrium in the face of stressful interpersonal encounters. We considered that such characteristics would be manifest in two settings: first, where an infant seated on its mother's lap is faced with an initially unreactive stranger; and second, where the infant is reunited with its mother after brief separations. On the basis of theoretical considerations as well as the results from a previous study of borderline mothers and their 2-month-old infants (Crandell, Patrick, \& Hobson, 2003), our secondary aim was to test the prediction that mothers with this diagnosis would show "intrusive insensitivity" toward their 12-month-old infants in a semistructured episode of play.

In outlining the background to the investigation, we begin by considering BPD and its 
potential importance for mother-infant relations. To our knowledge, there has been only one controlled study in which mothers with this disorder have been investigated with their infants, and we set the findings from that study in the context of cross-generational research with mothers who have other forms of psychopathology. Then we turn to methodological approaches relevant for the present investigation, focusing upon infant relatedness toward strangers and patterns of attachment relationship between infants and caregivers.

\section{BPD}

According to the Diagnostic and Statistical Manual of the American Psychiatric Association, Third Edition-Revised (DSM-III-R; American Psychiatric Association [APA], 1987), the diagnostic approach employed at the time the study began, individuals are said to have BPD when they meet five out of eight diagnostic criteria: a pattern of intense, unstable relationships; impulsiveness in at least two areas that are potentially self-damaging; affective instability; inappropriate, intense anger or lack of control of anger; recurrent suicidal threats or self-mutilating behavior; marked and persistent identity disturbance; chronic feelings of emptiness or boredom; and frantic efforts to avoid real or imagined abandonment. Although there is tentative evidence that temperamental factors such as impulsive aggression and affective instability may act as risk factors for the disorder (e.g., Posner, Rothbart, Vizueta, Thomas, Levy, Fossella, Silbersweig, Stern, Clarkin, \& Kernberg, 2003; Skodol, Siever, Livesley, Gunderson, Pfohl, \& Widiger, 2002), there is, as Posner et al. (2003, p. 1102) conclude, "currently no strong evidence that BPD is heritable." Much stronger evidence suggests that environmental factors such as child sexual abuse and other family influences such as maternal overinvolvement and inconsistency may play an important role in its pathogenesis (e.g., Bezirganian, Cohen, \& Brook, 1993; Herman, Perry, \& Van der Kolk, 1989; Ogata, Silk, Goodrich, Lohr, Westen, \& Hill, 1990; Patrick, Hobson, Castle, Howard, \& Maughan, 1994; Weaver \& Clum, 1993).
There are reasons to believe that BPD may be of special interest and importance for the study of mother-infant relations. First, clinical experience as well as more formal research (e.g., Hobson, Patrick, \& Valentine, 1998; Kernberg, 1976) suggests that individuals who have this pattern of emotional and relationship difficulties also have characteristic and potentially disturbing ways of relating to other people at the level of momentmoment interactions. For example, Hobson et al. (1998) reported a controlled study that demonstrated how, compared with a group of women with dysthymia, those with BPD tended to show forms of relatedness to a psychotherapist that were rated highly for paranoid-schizoid features such as clear or subtle indications of locked-in hostility and intense, idealizing, or denigrating exchanges. Clinically, such characteristics are associated with the operation of an especially intrusive form of psychic defense, projective identification, through which the individual stirs negative and disturbing feelings in others by evoking states of mind that mirror her own emotional conflicts (as discussed by several authors in Sandler, 1988). If such patterns of relatedness and interpersonal process are a feature of these individuals' relations with their infants, the impact on infant development might be substantial.

Second, there is evidence from controlled studies employing the Adult Attachment Interview (George, Kaplan, \& Main, 1985) that women with BPD tend to be "enmeshed" in representing their early attachments, and perhaps especially prone to "confused, fearful, and overwhelmed" (E3) states of mind that are rare and so far untested in relation to infant Disorganization. In addition, they are frequently unresolved with respect to trauma and loss (Barone, 2003; Fonagy, Leigh, Steele, Steele, Kennedy, Mattoon, Target, \& Gerber, 1996; Patrick et al., 1994). There is evidence that these attachment-related characteristics may influence mothers' relations with their infants, and in the case of unresolved trauma, predispose to the kinds of "frightened/ frightening" behavior thought to increase the likelihood of Disorganized infant attachments (Main \& Hesse, 1990). 
Third, there is the evidence from a previous controlled study of mother-infant relations where the mothers had BPD. In this study of 2-month-old infants (Crandell et al., 2003), we invited mothers to engage in face-face play with their infants for $2 \mathrm{~min}$, then adopt a "still-face" for $90 \mathrm{~s}$, and then resume play. In this context, mothers with BPD related to their young infants in a way that could be characterized as "intrusively insensitive." In response to the maternal still-face challenge, infants of these mothers showed more dazed looks and more looks away from the mother than did infants of nonborderline mothers. In the interactions that followed the still-face episode, infants of the control mothers seemed to recover to their earlier state, but among the borderline group, mother-infant exchanges were less satisfying and infant mood was relatively depressed compared with pre-stillface ratings. Already at 2 months of age, therefore, infants of borderline mothers were beginning to show distinctive characteristics under conditions of interpersonal stress.

These observations need to be set in the context of studies of mother-infant relations where the mothers have other kinds of psychiatrically defined psychopathology. The most extensive body of literature (reviewed in contributions to Murray \& Cooper, 1997) concerns the effects of maternal depression, where there are now several reports of marked disturbances in mother-infant interactions when the mothers come from disadvantaged circumstances. Depressed mothers have tended to be rated as hostile and intrusive, withdrawn, showing negative affect, or less sensitively attuned, and infant distress and avoidance have been common (e.g., Cohn, Campbell, Matias, \& Hopkins, 1990; Cohn, Matias, Tronick, Connell, \& Lyons-Ruth, 1986; Cohn \& Tronick, 1989; Field, Healy, Goldstein, \& Guthertz, 1990; Field, Healy, Goldstein, Perry, Bendell, Schanberg, Zimmerman, \& Kuhn, 1988; Field, Sandberg, Garcia, Vega-Lahr, Goldstein, \& Gay, 1985; Murray, Fiori-Cowley, Hooper, \& Cooper, 1996). Other studies have concerned early mother-child relations and/or attachment in the context of maternal anxiety disorder (Manassis, Bradley, Goldberg, Hood, \& Swinson, 1994), alcoholism and drug abuse
(O'Connor, Sigman, \& Brill, 1987; Rodning, Beckwith, \& Howard, 1991), eating disorders (Stein, Woolley, Cooper, \& Fairburn, 1994; Stein, Woolley, \& McPherson, 1999), and psychotic depression and mania (Hipwell, Goossens, Melhuish, \& Kumar, 2000).

\section{Hypotheses}

Our underlying hypotheses were threefold. Our first hypothesis was that through experience of particular forms of dysfunctional motherinfant relations over the first year of life, infants of mothers with BPD are prone to develop incoherent or segregated forms of "internal working models of relationships" (Bowlby, 1969; Bretherton \& Munholland, 1999), or what psychoanalysts view as troubled forms of "internal object relations" (e.g., Greenberg \& Mitchell, 1983; Guntrip, 1977; Hobson, 1997). Expressed more simply, we hypothesized that mothers with BPD relate to their infants in ways that are likely to result in the infant being less confident in the potential for rewarding emotional exchange with other people and less likely to show a robust, flexible, and organized emotional state when faced with a stranger. As a further reflection of these factors, but with specific reference to the mother-child relationship, we anticipated that a substantial proportion of the infants of borderline mothers would show behavioral Disorganization (arguably, a reflection of dissociated states of mind) in relation to their mothers in the Strange Situation. Third, we hypothesized that, just as women with BPD show characteristically intense and often intrusive relations with other adults, so their relations with their infants would be characterized by intrusive insensitivity, as indeed, we had found to be the case between mothers of this kind and their 2-month-old infants (Crandell et al., 2003).

\section{Methodological approaches to mother-infant relations}

Infant interpersonal relatedness. Our first methodological approach was intended to test infants' propensity for certain forms of interpersonal relatedness, and specifically, their 
quality of relating to a stranger under conditions of interpersonal stress. These conditions were designed to highlight individual differences among infants, and to yield insights into an infant's "internal object relations" (or internal working models) as these become realized in a current interpersonal exchange.

Previous approaches to analyzing infant interpersonal relatedness have drawn upon ethological concepts of interacting behavioral systems such as the attachment, exploratory, fear, and affiliation systems (e.g., Bretherton \& Ainsworth, 1974; Sroufe, 1977), and temperament perspectives in which the emphasis is upon infant characteristics such as emotionality, activity, and sociability (Buss \& Plomin, 1984), reactivity and self-regulation (Rothbart \& Derryberry, 1981), and behavioral inhibition (Garcia-Coll, Kagan, \& Reznick, 1984). There are three studies especially relevant for the present investigation, although each was conducted before Disorganized attachment patterns were recognized. In the first of these, Main and Weston (1981) tested 12month-olds for their readiness to establish a positive social relationship with an adult "clown" who tried to engage the infant during a play period in the mother's presence. Infants were judged by their active efforts to engage in eye-eye contact with the clown, their positive responses to the clown's initiations, their interest or delight in a game of ball, their affective response to the changing moods of the clown, and the degree to which their engagement seemed "personal" rather than wooden or overtaken by fear or distress. Each infant was also scored for "conflict behavior" during the clown session. On ratings for relatedness to the friendly adult, the mean scores for infants classified as secure with their mothers on the Strange Situation were almost twice as great as for those who were classified as insecure. Only one of the 23 infants classified as secure, but $57 \%$ of the 21 infants classified as insecure, showed signs of conflict.

The second study was conducted by Thompson and Lamb (1983; following Stevenson \& Lamb, 1979), who assessed the sociability of 12- and 19-month-old infants by having an unfamiliar female make a series of overtures toward the infant of gradually increasing in- trusiveness over a period of about $5 \mathrm{~min}$, including an attempt to engage the infant in give and take while the infant was on the mother's lap. The investigators reported a complex relationship between stranger sociability scores and Strange Situation attachment classification at each age. At 12 months, for example, infants in the B1 and B2 subgroups received high sociability scores, and infants in the A1, B4, and C2 subgroups received low scores. The researchers considered that, when infants were preoccupied with mother-directed contact maintenance, this precluded positive social interaction with another person.

Finally, aspects of the present study were inspired by a classic paper by the pediatricianpsychoanalyst Donald Winnicott (1941). Winnicott devised a procedure for assessing mothers with their infants that has certain features in common with the more recent technique of presenting infants with a "still-face challenge." Winnicott asked mothers of infants aged from 5 to 13 months to sit opposite him with the angle of a table coming between the mother and himself. She sat with her baby on her knee. Winnicott placed a shiny tongue depressor at the edge of the table and conveyed how he wished the adult to contribute as little as possible to what happened next. Within this quasiexperimental setting, Winnicott observed certain regularities but also important individual differences in the infants' responses. In the initial phase, an infant would reach for the spatula, pause, and look at Winnicott himself and the mother with big eyes; after this "period of hesitation," the infant would relax and bring the spatula to its mouth, and might bang it or pretend to feed one of the adults; and finally, the infant would drop or throw the spatula down and have it returned repeatedly. Winnicott considered that "any variation from that which I have come to regard as the norm of behavior in the set situation is significant" (Winnicott, 1941, p. 56; see also Jackson, 1996). In this way, Winnicott explored how when infants were seated on their mothers' lap, close observation of their reactions to a quiet stranger might reveal warning signs of incipient maladaptation.

In our own Modified Set Situation, a stranger sat facing the infant for a short period 
in which she offered minimal feedback, as a spatula lay on the corner of a table between them. Then there was a second phase to the procedure in which the experimenter "softened" and attempted to engage the infant as sensitively as possible in a game of give and take with the spatula (see also Gustafson, Green, \& West, 1979; Hay \& Murray, 1982; Reinecke \& Fogel, 1994).

Patterns of attachment. Our second approach was to assess infants' reactions to separations from and reunions with their mothers in the Strange Situation of Ainsworth and Wittig (1969; Ainsworth, Blehar, Waters, \& Wall, 1978). This assessment procedure yields categories with respect to the "organizational construct" of attachment, through ratings of interactive behavior. The most important of the rating scales concern proximity or contact seeking, contact maintenance, resistance, and avoidance upon reunion, although infants' search behavior during separation and distance interaction also play significant roles.

We had anticipated that the category of Disorganized attachment would be especially important for the present study. Main and Solomon $(1986,1990)$ described how some infants show "disorganized/disoriented" behavior including contradictory attachment behavior patterns such as very strong attachment followed by avoidance, misdirected or interrupted movements and expressions, anomalous postures, freezing and stilling, fearful expressions, and manifestations of disorientation such as confused or dazed expressions, or multiple rapid changes in affect. As van IJzendoorn, Schuengel, and BakermansKranenburg (1999) conclude from their metaanalysis of the precursors, concomitants, and sequelae to Disorganized attachment in early childhood, not only is it possible to identify such patterns of attachment in a reliable way, but also these have predictive validity for children's subsequent problems such as externalizing, controlled-controlling, and dissociative behavior. Drawing on this meta-analysis, Lyons-Ruth and Jacobvitz (1999) review how estimates of the prevalence of Disorganized attachment range from 13 to $82 \%$, depending on the presence and types of family risk fac- tors, among which parental maltreatment (e.g., Carlson, Cicchetti, Barnett, \& Braunwald, 1989), chronic and bipolar depression (e.g., DeMulder \& Radke-Yarrow, 1991; Teti, Gelfand, Messinger, \& Isabella, 1995), and parental unresolved early loss or trauma (van IJzendoorn, 1995) are important.

As in the case of other aspects of attachment, there is meagre evidence that Disorganized attachment has high heritability (e.g., Bokhorst, Bakermans-Kranenburg, Fearon, van IJzendoorn, Fonagy, \& Schuengel, 2003; O'Connor \& Croft, 2001; but see also Lakatos, Nemoda, Toth, Ronai, Ney, SasvariSzekely, \& Gervai, 2002, for evidence of a genetic contribution). Although the search is underway for physiological correlates (Spangler \& Grossmann, 1999), it is critically important to determine whether particular qualities of caregiver-infant relatedness predispose to this attachment pattern. There is some support for the suggestion by Main and Hesse (1990) that maternal frightened/ frightening behavior (including dissociative states), often associated with unresolved traumatic and/or frightening experiences in the mother, may result in Disorganization through collapse of the infant's behavioral and attention strategies (Lyons-Ruth, Bronfman, \& Parsons, 1999; Schuengel, BakermansKranenburg, \& van IJzendoorn, 1999; van IJzendoorn et al., 1999). Although there is mixed evidence whether maternal insensitivity per se might predispose to Disorganized attachment (Carlson, 1998; van IJzendoorn et al., 1999), Lyons-Ruth, Bronfman, and Parsons (1999) have presented evidence that other features of disrupted maternal affective communication such as negative-intrusive behavior and role confusion, and hostile/helpless organization of parent-infant exchanges, may play causative roles. As van IJzendoorn et al. (1999, p. 225) observe, "the search for the mechanisms leading to disorganization has just started."

These explorations of the origins of Disorganized attachment are in keeping with an emphasis within the broader domain of developmental theory, that an infant's relationships are founded upon and mediated through interpersonal interactions between a caregiver 
and baby (Ainsworth et al., 1978, p. 142; Brazelton, Koslowski, \& Main, 1974; Stern, 1985; Tronick \& Cohn, 1989). Substantial effort has been deployed to determine the relative importance of potentially separable components of maternal sensitivity for attachment relationships (e.g., De Wolff \& van IJzendoorn, 1997; Schneider Rosen \& Rothbaum, 1993) and their interaction with other factors such as infant temperament characteristics or family and cultural values (e.g., Fox, Kimmerly, \& Schafer, 1991). Although the present study does not attempt to evaluate these factors, for example, we do not have measures of maternal relatedness over the months preceding the testing session, nor do we have assessments of infant temperament or other indices of constitutional predisposition to atypical patterns of attachment, we do include a measure of one aspect of current mother-infant interaction that might be especially relevant for borderline psychopathology, namely, maternal intrusive insensitivity. This we assessed in semistructured play with a toy train, following Trevarthen and Hubley (1978).

In view of our small groups, we restricted the number of predictions derived from the hypotheses outlined earlier. With regard to the infants' emotional state and behavior in the Modified Set Situation, we made predictions at three levels of measurement: first, at an explicitly interpersonal level of emotional contact (rated by subjective judgments of relatedness), we predicted that the infants would be rated as lower in availability for positive engagement; second, at a level of behavioral organization and mood state, we predicted that infants of borderline mothers would achieve low scores on summed ratings of flexibility, alertness, organization of behavior, and affect; and third, on a more molecular behavioral level of interpersonally directed behavior, we predicted that they would manifest a lower proportion of positive looks to the stranger. As a subsidiary prediction on the level of reciprocal behavior, we predicted that in the give and take phase of the procedure, fewer of these infants would give the spatula to the stranger. With regard to the infants' ratings in the separation-reunion assessment of the Strange Situation, we predicted that infants of border- line mothers would manifest a Disorganized pattern of attachment. Fourth, we predicted that when playing with their infants, the borderline mothers would be rated as high on "intrusive insensitivity."

\section{Method}

\section{Participants}

Ten mothers with BPD participated in the study, together with a control group of 22 mothers who had no clinical features of BPD, or other history of psychiatric disorder, matched as far as feasible (but not exactly) for age, ethnicity, social class, marital status, and education (Table 1).

Mothers and their babies were recruited through screening at antenatal clinics, and through advertisements placed in local publications. Participants were blind to the aims of the study, and were told only that the project would be investigating relationships between mothers and infants, and infant development at the end of the first year of life. In addition, a member of the study team was available to discuss what participation in the study would involve.

Screening of potential participants involved questionnaires for ascertaining demographic information and for providing initial evidence regarding diagnosis. This was the first of two stages in making the diagnosis of BPD or mental disorders in accordance with the criteria in the DSM-III-R (APA, 1987). In the stage of screening, mothers were asked to complete the questionnaire version of the Structured Clinical Interview for DSM-III-R (SCID-NP; Spitzer, Williams, Gibbon, \& First, 1990), and a questionnaire version of the SCID overview and "module A" focusing on mood syndromes and "module B/C" (the "psychotic screen"). Mothers who met the criteria for BPD and no other disorders were invited for interview and were given the SCID-II interview focusing on personality disorders supplemented with the interview version of the SCID overview and modules A and B/C. Only those women meeting the diagnostic criteria for BPD and no other diagnostic categories were recruited for the borderline group. Mothers were accepted 
Table 1. Participant characteristics by diagnostic group

\begin{tabular}{|c|c|c|}
\hline & \multicolumn{2}{|c|}{ Diagnostic Group } \\
\hline & $\operatorname{BPD}(n=10)$ & Control $(n=22)$ \\
\hline \multicolumn{3}{|c|}{ Infant Characteristics } \\
\hline \multicolumn{3}{|l|}{ Infant age (weeks) at testing } \\
\hline Mean $(S D)$ & $53(2.8)$ & $55(1.8)$ \\
\hline Range & $47-57$ & $52-58$ \\
\hline \multicolumn{3}{|l|}{ Birthweight (lb) } \\
\hline Mean & 6 & 7 \\
\hline Range & $5-8$ & $5-10$ \\
\hline Infant gender $(\mathrm{M}: \mathrm{F})$ & $5: 5$ & $11: 11$ \\
\hline \multicolumn{3}{|c|}{ Maternal Characteristics } \\
\hline \multicolumn{3}{|l|}{ Maternal age (years) } \\
\hline Mean $(S D)$ & $32(7)$ & $33(4)$ \\
\hline Range & $18-41$ & $25-42$ \\
\hline \multicolumn{3}{|l|}{ Length of pregnancy (weeks) } \\
\hline Mean & 40 & 39 \\
\hline Range & $36-52$ & $34-41$ \\
\hline \multicolumn{3}{|l|}{ Demographic information: $n(\%)$} \\
\hline \multicolumn{3}{|l|}{ Ethnicity } \\
\hline Asian & 0 & $2(9 \%)$ \\
\hline Afro-Caribbean & $4(40 \%)$ & $4(18 \%)$ \\
\hline Caucasian & $6(60 \%)$ & $16(73 \%)$ \\
\hline \multicolumn{3}{|l|}{ Social class } \\
\hline I-II & $6(60 \%)$ & $16(73 \%)$ \\
\hline III-IV & $4(40 \%)$ & $6(27 \%)$ \\
\hline \multicolumn{3}{|l|}{ Marital status } \\
\hline Married/cohabitating & $6(60 \%)$ & $16(73 \%)$ \\
\hline Single/divorced & $4(40 \%)$ & $6(27 \%)$ \\
\hline \multicolumn{3}{|l|}{ Educational achievement } \\
\hline Preliminary high school exams & 0 & $1(5 \%)$ \\
\hline Higher school exams & $7(70 \%)$ & $12(54 \%)$ \\
\hline University & $3(30 \%)$ & $9(41 \%)$ \\
\hline
\end{tabular}

into the control group providing that on screening and interview they showed no features of BPD and did not meet diagnostic criteria for any other $D S M-I I I-R$ disorder, either current or past.

The gender ratio of infants in each group was exactly half male and half female. In all but 1 case (a further one had missing data), the infants of mothers with BPD had experienced the mother as the primary caregiver, and the exception was where care was shared between mother and father. In 4 cases, the infant under study was the only child, in 2 cases the second child, and in 1 case each the infant came third, fourth, fifth, and sixth in the family. Four mothers reported difficult births (in three cases requiring a forceps or ventouse delivery), but only 1 of these infants was admitted to a special care baby unit and, for 1 infant, data were missing. Among infants of the control mothers, 19 had experienced the mother as the primary caregiver, in 2 cases care was shared with father, and the final case also had a nanny. In 11 cases, the infant under study was the only child, in 9 cases it was the second child, and in the remaining 2 cases it was the third. Six mothers reported difficult births (two requiring a forceps delivery), but only 2 of these infants were admitted to special care baby units. 


\section{Procedure}

The Modified Set Situation. One of the two investigators greeted the mother-infant pairs outside the testing room, and offered refreshments so that mothers and infants were able to settle comfortably. The investigator explained to the mother what was going to happen, and asked that as far as possible, she should allow her infant to deal with the situation in his or her own way, without too much intervention. The mother and baby were then asked to enter the testing room by themselves, and the investigator operated a remote-controlled videotape camera to record what happened.

In the testing room a female investigator was waiting. This person had met neither mother nor baby before. She was seated at the corner of a table on which there was lying a washed shiny spatula. The investigator stood up as mother and baby entered, and with a neutral facial expression and gesture, indicated a chair that was positioned across the corner of the table. The mother took this chair and, as she had been instructed, sat with her infant facing away from her on her lap, so that the edge of the table and the spatula were potentially within the infant's reach. The investigator sat across the table corner facing the infant, approximately the same distance away from the spatula as the mother, so that both infant and investigator would need to lean forward and stretch out an arm if they wanted to touch the spatula.

The procedure was divided into two phases. Phase 1, the still-face phase, lasted approximately $90 \mathrm{~s}$. The investigator sat quiet and motionless as she watched the baby steadily. She was not staring at the baby, nor did she assume a glazed look, but instead was available to look into the baby's eyes in a contemplative but neutral way without reacting to any bids for engagement. The infant was free to relate to the investigator, the spatula, and the mother. Although it may seem that this was a threatening situation, and was intended to highlight individual differences in the ways infants experienced and dealt with an unreactive stranger, it should be recalled that the infant was seated on the mother's lap, and therefore with the mother close by for reassur- ance should this be needed. In the event, the arrangement very rarely caused the infant marked distress, and not a single infant cried.

Phase 2 involved rapprochement and give and take. At the end of the first phase, the investigator "softened" by gently leaning forward slightly and whispering to the child, and indirectly to the mother, in a reassuring manner. Her aim was now to behave in as sensitive and natural a way as possible, to engage the infant in a communicative exchange. She was careful not to be intrusive, but was free to smile or offer other encouraging emotional expressions. If the infant was not already playing with the spatula, the investigator would nudge it slightly closer to the infant, indicating that it was available for the infant to pick up.

When the investigator judged that the infant had reached a "steady state" of emotional engagement or nonengagement with herself and the spatula, and whether or not the infant had by now picked up the spatula, she gently retrieved the spatula from the infant or picked up the spatula from the table, and then offered it to the infant on a palm-up outstretched hand. She tried her best to encourage the infant to take the spatula, and if the infant did so, she waited a short while and then asked for the spatula back, again by a combination of verbal coaxing and palm-up hand gestures. Whether or not the infant participated in give and take, the investigator made three such attempts at turn taking.

Rating procedures for the Modified Set Situation were based partly on the approach of Murray and Fiori-Cowley (Murray et al., 1996). Infants were rated separately on the first and second phases of the procedures, and scores on the two phases were combined to form a total score for each aspect of relatedness. The principal rater was blind to diagnostic groups and the hypotheses and predictions of the study, and a second nonblind rater provided independent judgments for reliability purposes on $31 \%$ (five borderline and five control dyads) of the cases. Details of each set of ratings follow.

Availability for positive engagement. For each phase, the ratings ranged from a score of 0 if the infant showed virtually no signs of expect- 
ing or anticipating positive engagement with the investigator as a potentially benign, interesting, or playful figure to a score of 4 if the infant was judged to display repeated, active bids to engage the examiner in some sort of reciprocal social contact. Across the two phases, ratings were significantly correlated $(r=.65, p<.01)$ and similar in magnitude ( $M=2.4, S D=1.5$ for the first phase, and $M=2.4, S D=1.2$ for the second), a pattern that held for each group. Interrater reliability for the total scores (combining the two phases) was high (intraclass correlation coefficient $[\mathrm{ICC}]=.94)$.

Behavioral organization and mood state. The index of behavioral organization was a composite score on four items of the Murray and Fiori-Cowley scheme, each rated on a 5-point scale. The four subscales concerned (a) affect, from $0=$ expressions of marked negative affect to $4=$ marked positive affect; (b) alertness, from $0=$ inert or passive much of the time to 4 = lively, active gestures, and actions for much of the time; (c) organization, from $0=$ unable to manage the situation, fluctuating between troubled states of mind (e.g., dazed and fearful) to $4=$ organized, composed, and steady throughout the testing session; and (d) flexibility of affect, from $0=$ either little or no ability to shift flexibly among affective states, with watchfulness, fearfulness, or "cutoff" affect or abrupt swings from one state to another to $4=$ a high level of flexibility of affect throughout session. Ratings on these four subscales were highly intercorrelated (with four of the six intercorrelations above .5), supporting our a priori decision to use a composite score. Across the two phases of the procedure, the composite scores were significantly correlated $(r=.71, p<.01)$ and similar in magnitude $(M=10.6, S D=3.9$ and $M=10.7, S D=3.3$, respectively), a pattern that held within each group. Interrater reliability on the overall composite score was high $(\mathrm{ICC}=.93)$.

Percentage of infant positive looks to the stranger. This index was chosen as a specific form of behavior that might reflect an important aspect of interpersonal relatedness. The percentages were calculated by counting every look to the stranger and calculating the proportion that were coded as positive (i.e., involving a smile or friendly vocalization). Across the two phases of the procedure, the scores were both significantly correlated $(r=$ $.65, p<.01)$ and similar in magnitude $(M=$ $47 \%, S D=37.4 \%$, and $\mathrm{M}=53 \%, S D=$ $35.7 \%$ ), a pattern that held within each group. Interrater reliability for judging percentage of positive looks was high $(\mathrm{ICC}=.96)$.

Give and take with the spatula. Here we concentrated on whether the infant could be coaxed into giving the spatula to the stranger, and simply rated whether this occurred.

The Strange Situation. In the final phase of the testing session, the investigator suggested that the mother sit with the child on the floor, where some toys were available, and to settle the infant in play. The investigator withdrew to leave the mother and infant together. Once the infant had settled, we conducted the standard Strange Situation test of separations and reunions between mother and infant, with a female adult acting as the stranger, as described by Ainsworth and Wittig (1969) and Ainsworth et al. (1978).

Ratings of the separation-reunion episodes were conducted according to standard procedures by an experienced rater (Elizabeth Carlson) trained and certified reliable by a team of expert coders including Mary Ainsworth and Alan Sroufe (ABC classification) and Mary Main (D classification). She was blind to the hypotheses underlying the study, the fact that a group of borderline mothers was being tested, and group membership. Independent blind ratings conducted on 20 randomly selected cases, classified according to the four standard attachment categories (including Disorganized), revealed substantial interrater reliability $(\kappa=.83)$.

Maternal relatedness in play. Between the Modified Set Situation and the Strange Situation Test, there was a 2-min period of motherchild interaction in which the mother was seated across the corner of a table from her infant, and was given a plastic toy train with two figures and asked to teach her infant how 
to play with this and put the figures into the train (after Trevarthen \& Hubley, 1978).

Full details of our approach to assessing maternal intrusive insensitivity (adapted from Murray et al., 1996) appear in a companion publication (Hobson, Patrick, Crandell, García-Pérez, \& Lee, 2004), where kappa coefficients for interrater reliabilities on 5-point ratings were .51 for sensitivity and .75 for intrusiveness (moderate and substantial agreement, respectively, according to Landis \& Koch, 1977). The rating for sensitivity concerned the mother's awareness of the infant's state, together with appropriate adjustment to this, and her mostly warm and accepting attitude; the rating for intrusiveness concerned the extent to which the mother's actions cut across, took over or disrupted the infant's activities, or insistently demanded interaction when the infant was self-absorbed or looking away. There was a high negative correlation between the two ratings (Pearson's $r=-.74$, $p<.001$ ), and by reverse scoring the sensitivity ratings, they were combined to yield the current measure of intrusive insensitivity (with a maximum score of 8 representing the highest ratings for insensitivity and lowest for intrusiveness). With the present sample, the ICC for ratings of intrusive insensitivity was .71.

\section{Results}

\section{Infant measures in the Modified Set Situation}

Availability for positive engagement. Infants of mothers with BPD scored lower on availability for positive engagement $(M=3.2, S D=$ 2.0 , range $=0-6)$ than did infants of comparison mothers $(M=5.4, S D=2.3$, range $=$ $0-8), t(30)=2.6, p<.05$. (Here, as in all subsequent analyses, we provide $p$ values at a two-tailed level of significance.) Only 2 of the 10 infants of mothers with BPD versus 15 of the 22 comparison infants scored above 4 (out of 8 ).

Behavioral organization and mood state. Infants of mothers with BPD scored lower on behavioral organization and mood state $(M=$ $17.8, S D=4.7$, range $=12-28)$ than did infants of comparison mothers $(M=22.9, S D=$
7.0$, range $=10-32), t(30)=2.1, p<.05$. Only one infant of the borderline group versus over half the comparison group scored above 21 on this scale.

Percentage of positive looks. As a preliminary step, we determined that the overall number of looks to the stranger was closely similar for the group of infants with borderline mothers $(M=19.6, S D=7.6)$ and the comparison infants $(M=18.5, S D=5.4)$. As predicted, infants of mothers with BPD showed a smaller percentage of positive looks to the stranger $(M=27.5 \%, S D=17.4 \%$, range $=7-62 \%)$ than did infants of comparison mothers $(M=$ $56.8 \%, S D=34.2 \%$, range $=0-100 \%)$, $t(30)=3.2, p<.01$. Only one infant of the borderline group versus over half the comparison group made more than $50 \%$ of looks to the stranger that were positive.

Give and take. Although we had predicted that a lower proportion of infants of mothers with BPD would give the spatula to the investigator in the give and take game, this proved not to be the case: 6 out of 10 of this group gave the spatula on at least one occasion, compared with 9 out of 22 infants in the comparison group.

\section{The Strange Situation}

Details of the attachment classifications are presented in Table 2.

Disorganized attachment. Our principal prediction was that infants of mothers with BPD would show a higher prevalence of Disorganized attachment than infants of mothers without psychopathology. This prediction was borne out: in no fewer than eight of the 10 $(80 \%)$ infants of mothers with BPD, but in 6 of the $22(27 \%)$ comparison infants, the infants were judged to be Disorganized (Fisher's exact $p=.008)$. The group contrast remained significant $(p=.02)$ when the one control infant with a primary classification of B but alternate D was counted as Disorganized.

For illustrative and exploratory purposes, we present data for the Disorganized and nonDisorganized infants from each group in 
Table 2. Strange Situation classifications

\begin{tabular}{lcc}
\hline \hline & \multicolumn{2}{c}{ Diagnostic Group } \\
\cline { 2 - 3 } Classification & $\begin{array}{c}\text { BPD } \\
(n=10)\end{array}$ & $\begin{array}{c}\text { Control } \\
(n=22)\end{array}$ \\
\hline A2 & 0 & 1 \\
B2 & 2 & 3 \\
B3 & 0 & 1 \\
B4 & 0 & 9 \\
B4/D & 0 & 1 \\
C1 & 0 & 1 \\
D/A/C & 1 & 1 \\
D/A2 & 3 & 3 \\
D/B1 & 0 & 1 \\
D/B2 & 3 & 1 \\
D/C1 & 1 & 0 \\
\hline \hline
\end{tabular}

Table 3. We conducted a limited set of exploratory comparisons among subgroups (here, $p$ values are merely suggestive), as follows:

1. With these small samples, there were no significant group differences between the two subgroups of Disorganized infants.

2. Given the confound between diagnosis and Disorganized attachment in the group with borderline mothers, it seemed appropriate to seek possible concomitants of Disorganized attachment within the nonborderline group. The limitation of this approach was that the group of Disorganized infants was small $(n=6)$. In the event, as shown in Table 3, there was a single significant difference between Disorganized and nonDisorganized control infants in the Modified Set Situation, but the other measures showed consistent nonsignificant trends in the same direction.

3. When we considered combining the two non-Disorganized infants of the borderline group with those of the control group, it became clear that this might aggregate infants who were markedly different. For it is apparent from Table 3 that the two seemingly "secure" (B2) infants in the borderline group were on the extreme end of the distribution of scores for relatedness in the Modified Set Situation, just as their mothers were especially intrusively insensitive.
When we reexamined the videotapes in consultation with the original blind rater, our observations accorded with each of these measures: in the Modified Set Situation, one of the infants was wary, inhibited, and showed dazed looks, and the other appeared "blunt" in affect and tended to give the stranger very long stares; in the Strange Situation, the former of the two infants showed some signs of Disorganization (such as repeated approaches to and reaches for his mother followed by avoidant postures, such as turning quickly from his mother's lap), and the second infant seemed flat in affect, bewildered in the presence of the mother and more attentive with the stranger, and again showed some dazed expressions and lethargic movements; and in the teaching task, both mothers were ill attuned and very intrusive. It appears likely that these infants comprise atypical cases within the B2 category. In each case, upon further review of the Strange Situation tapes, our original rater considered the infants to be near the threshold for the category of Disorganized attachment.

4. The final exploratory comparisons, therefore, were between the Disorganized infants across the two groups $(n=14)$ and the non-Disorganized infants in the control group $(n=16)$. As shown in Table 3 , there were consistent group differences on measures from the Modified Set Situation.

\section{Maternal intrusive insensitivity}

The borderline mothers were significantly more intrusively insensitive $(M=6.0, S D=1.1)$ than comparison mothers $(M=4.1, S D=$ 2.5), $t(30)=2.9, p<.01$. All but one mother in the borderline group scored 5 or above for intrusive insensitivity, but this was the case for fewer than half the comparison group, whose scores were widely distributed across the range of scores. It is of note that the two borderline mothers whose babies were categorized as B2 on the Strange Situation were among the most intrusively insensitive of all (see Table 3).

To explore possible associations between maternal intrusive insensitivity and infant in- 
Table 3. Data for Disorganized and Nondisorganized subgroups

\begin{tabular}{|c|c|c|c|c|c|c|c|c|c|c|}
\hline & \multicolumn{6}{|c|}{ Disorganized Infants } & \multicolumn{4}{|c|}{ Nondisorganized Infants } \\
\hline & \multicolumn{2}{|c|}{ Control $(n=6)^{a, b}$} & \multicolumn{2}{|c|}{$\operatorname{BPD}(n=8)^{a}$} & \multicolumn{2}{|c|}{ Total $(n=14)^{c}$} & \multicolumn{2}{|c|}{ Control $(n=16)^{b, c}$} & \multicolumn{2}{|c|}{$\mathrm{BPD}(n=2$} \\
\hline & $M$ & $S D$ & $M$ & $S D$ & $M$ & $S D$ & $M$ & $S D$ & $M$ & $S D$ \\
\hline \multicolumn{11}{|l|}{ Infants } \\
\hline Availability for positive engagement & 4.7 & 2.5 & 3.6 & 2.0 & $4.1^{c}$ & 2.2 & $5.7^{c}$ & 2.3 & 1.5 & 0.7 \\
\hline Behavioral organization and mood state & $17.3^{b}$ & 5.3 & 18.6 & 4.8 & $18.1^{c}$ & 4.9 & $25.0^{b, c}$ & 6.4 & 14.5 & 2.1 \\
\hline Percentage of positive looks & 40.3 & 29.9 & 32.2 & 16.1 & $35.7^{c}$ & 22.3 & 62.9 & $34.5^{c}$ & 8.5 & 2.6 \\
\hline Give spatula in "give and take" (no. of infants) & 4 & $67 \%$ & 2 & $25 \%$ & 6 & $43 \%$ & 7 & $44 \%$ & 2 & $100 \%$ \\
\hline \multicolumn{11}{|l|}{ Mothers } \\
\hline Intrusive insensitivity & 4.8 & 2.1 & 5.7 & 1.0 & 5.4 & 1.6 & 3.9 & 2.7 & 7.0 & 1.4 \\
\hline
\end{tabular}

Note: Exploratory comparisons were conducted for subsets $a-c$ : uncorrected for multiple comparisons, $p<.05$ (two tailed) where indicated by superscripts; otherwise, ns.

${ }^{a}$ Disorganized BPD $(n=8)$ vs. Disorganized control $(n=6)$ : all $n \mathrm{~s}$.

${ }^{b}$ Disorganized control $(n=6)$ vs. Nondisorganized control $(n=16)$

${ }^{c}$ Total sample Disorganized $(n=14)$ vs. control Nondisorganized $(n=16)$. 
terpersonal behavior in the Modified Set Situation, we first considered the overall pattern of correlations among the 32 mother-infant dyads. Maternal intrusive insensitivity was not associated with infant availability for positive engagement $(r=-.16)$, behavioral organization and mood $(r=-.24)$, nor percentage of positive looks $(r=-.12)$, a lack of association that also held within each group; nor was intrusive insensitivity associated with infants' tendency to give the spatula to the investigator (scores for intrusive insensitivity for the 15 infants who gave the spatula, $M=4.6$, $S D=2.5$, and for the 17 infants who did not, $M=4.8, S D=2.3, n s)$. In the case of the comparison between the 14 Disorganized infants from both groups, and the 16 nonDisorganized and nonborderline infants, there was not a significant group difference in maternal intrusive insensitivity, but given that there was a medium effect size $(d=.66)$, group differences may have been evident in a larger sample. The data provided in Table 3 yields suggestive evidence (only) that among the nonborderline group with Disorganized infants, degree of maternal intrusive insensitivity was intermediate between that of the remaining control mothers, and those with BPD.

\section{Demographic variables}

A series of linear regression analyses in which maternal ethnicity, social class, marital status and maternal education, as well as infant gender and birth order, were entered one at a time, indicated that group differences in infant relatedness, infant attachment status, and maternal intrusive insensitivity remained after these demographic variables were taken into account. Inspection of the results revealed that different demographic characteristics were relatively evenly spread across the range of scores within each group, and the regression analyses confirmed a lack of association between demographic and mother/infant measures.

\section{Discussion}

In one respect, the results from this study are clear-cut. Three sets of predictions with which we embarked on this study were borne out. First, we predicted that tests of relatedness toward an initially unreactive stranger would reveal that infants of mothers with BPD are not only less available for positive engagement, but also less organized and positive in their emotional state. Second, we predicted that these infants would tend to be Disorganized in their pattern of attachment with their mothers, as tested in the Strange Situation. Third, we predicted that in a play/teaching task, borderline mothers would tend to manifest intrusive insensitive behavior. In each respect, there were significant group differences between the borderline and nonborderline mothers and their infants, in the expected direction. With regard to attachment status, there was even suggestive evidence that the two infants with borderline mothers who did not fall into the Disorganized category were atypical of B2 infants, not least with respect to their unusual forms of relatedness toward the stranger in the Modified Set Situation. These two cases might have something in common with those high-risk infants identified by Lyons-Ruth and colleagues as showing "unstable avoidance" but also classifiable as B2 (Lyons-Ruth, Connell, Zoll, \& Stahl, 1987; Lyons-Ruth, Repacholi, McLeod, \& Silva, 1991). Fourth, there was one prediction that was not fulfilled, in that the infants of each group did not differ in their propensity to engage in give and take with the spatula.

To assess what these results mean, and to consider how additional findings fill out the picture, it is appropriate to begin by highlighting certain limitations of the study.

First, although this is the most substantial group of mothers with a research diagnosis of BPD so far studied with their infants in a controlled investigation, a fact that relates to the difficulty in locating such mothers and securing their collaboration, it needs to be acknowledged that the group size was small. Therefore, one might question how far the sample were representative of mothers with this diagnosis, especially when they were mostly volunteers who responded to advertisements, and were relatively high in social class and education. Given the strict diagnostic procedures that we followed, however, and given that adverse so- 
cial and environmental factors that sometimes accompany the diagnosis were kept to a minimum, it is probable that ours was a conservative test of the abnormal characteristics of this psychopathological condition. Having said this, our decision to select borderline individuals without comorbidity places constraints on what we can conclude about the generalization of current findings to the broader group of mothers with this diagnosis.

Second, the control group of mothers and infants, although similar in many respects to the group with borderline mothers, were not precisely matched according to all potentially important variables, and so it remains open to question whether these variables might have contributed to the group differences. For example, the presence of a cohabiting partner is only a crude measure of social support, and such support may be important in enabling stressed caregivers to relate to their infants sensitively (e.g., Crockenberg, 1981); or from a complementary perspective, assessments of social class provide a less than elaborate index of social adversity. It was also the case that we had no data on the quality of paternal input to the care of the infants. On the other hand, the bias toward higher social classes and educational history in both groups of mothers and infants, and the relatively high rates of cohabitation with a partner, render it unlikely that such factors could account for the observed group differences. In addition, the demographic variables were unrelated to our measures, both across and within the two groups.

Perhaps most critically, the nature of the control group limits claims that may be made about the specificity of the observed patterns of infant and maternal relatedness to the condition of BPD. The control group were selected as mothers who were free of psychopathology. The important advantage of this approach was that we could judge the results that emerged from the novel testing situation of the Modified Set Situation in the context of responses by relatively "typical" mothers and infants. In addition, we could begin to explore how far characteristics such as infant Disorganized attachment and maternal intrusive insensitivity had a bearing upon measures of infant related- ness, independent of psychopathology. However, it is entirely plausible that mothers with other psychopathological conditions would have contrasted with our "typical" control group. In the introduction, for example, we noted how depressed mothers may be distinguished from nondepressed mothers by showing intrusive or withdrawn relations with their infants. Therefore, it remains to establish the degree to which the present findings are specific to BPD.

It is here that we can begin to take up some of the more subtle findings. Consider the results on maternal intrusive insensitivity. We examined this aspect of maternal relatedness not because we considered it captured the essence of mother-infant relations for mothers with BPD, but rather, because we anticipated it would reflect one characteristic feature of the disorder that could easily be measured. Our reasoning was that if such intrusive insensitivity characterized these mothers, then this might suggest that interpersonal psychopathology of a specific quality might have a bearing on the development of the infants in this group. Of course, we did not suppose that intrusive insensitivity was the prerogative of borderline mothers alone, and what the results revealed was that, whereas almost all the borderline mothers could be categorized in this way, this was true of only a modest proportion of the control group. On the other hand, maternal intrusive insensitivity per se was not correlated with measures of infant relatedness, and its equivocal relation to Disorganized attachment status is in keeping with other evidence that this category of attachment is not explained by customary measures of maternal sensitivity (van IJzendoorn et al., 1999).

The upshot of these findings is that mothers with borderline personality tend to be intrusively insensitive, but insofar as maternal relatedness is causally related to infant sociability, it appears to be the manner or quality of this intrusive form of relatedness that is most important for infant development. This conclusion is in keeping with clinical practice on the one hand, and with our previous research with women with BPD on the other. The critical clinical feature of borderline psychopathology, at least within therapeutic relationships, is that individuals with the DSM 
syndrome of unstable relationships and mood states accompanied by disturbances of identity and self-harming behavior are also individuals prone to stir up extremely strong and conflicting feelings and impulses in people with whom they relate (e.g., Gunderson, 2001). This is more than a matter of intrusiveness, although this is one feature of their social engagement; as research evidence has confirmed (Hobson et al., 1998), it also appears to reflect these patients' malign experiences of other people, for example, as persecutory or idealized. The intensity and brittleness of their interpersonal exchanges, sometimes involving abrupt switches in attitude (e.g., from a seductive to a contemptuous stance), is correspondingly disturbed and disturbing for others. These clinical observations are relevant for weighing up which factors beyond (and perhaps in combination with) intrusive insensitivity may be contributing to infant Disorganization.

There are two additional leads in this respect. First, both an early study of our own that employed the Adult Attachment Interview with borderline women (Patrick et al., 1994) and other more recent studies (Barone, 2003; Fonagy et al., 1996) suggest that these individuals not only tend to show particular forms of "enmeshed" attitudes to attachment, but also are often unresolved with respect to trauma and loss. In our own study of Adult Attachment, for example, the rates of trauma and loss were equivalent in two small groups of borderline and depressed women, but only in the former group was unresolved status almost universal (in 9 out of 12 women). We have already reviewed evidence that unresolved trauma and loss may predispose mothers to show frightened/frightening behavior toward their infants, and that such behavior is linked with infant Disorganized attachment.

Second, Lyons-Ruth and colleagues (e.g., Lyons-Ruth, Bronfman, \& Atwood, 1999) have presented a "relational diathesis model" for Disorganized infant attachment. In many respects, this model is in keeping with psychoanalytic theories that posit dyadic structures of interpersonal relatedness in which infants may not only experience, but also identify with, aspects of other people's relations with themselves (Hobson, 2002). LyonsRuth has stressed how hostile/helpless relations between a mother and infant may predispose to Disorganized attachment, and in a recent collaborative study (Melnick, Patrick, Lyons-Ruth, \& Hobson, 2003), we have found evidence for a high prevalence of hostile/helpless states of mind in women with BPD compared with depressed patients. Such relational patterns may prove to be important for borderline mothers' relations with their infants.

From a complementary perspective, it is important not to overlook the potential importance of factors that may be prevalent among, but not specific to, the syndrome of BPD. For example, there is evidence that even in the absence of defined psychopathology, maternal intrusiveness and insensitivity may influence infants" tendency to engage in "triadic" person-person-world relations in which they share or coordinate their experiences of objects and events with someone else (Hobson et al., 2004). Or again, one needs to consider the sources of between-group similarities, for example, those between the Disorganized subgroups of borderline and nonborderline infants in the present study.

Whatever factors in mother-infant relatedness correspond with infant characteristics, it remains to establish how such correspondence comes about in the course of early development. The evidence from a crosssectional study such as this cannot decide the degree to which mothers may have shaped infant development, infants may have shaped maternal relatedness, or genetic/constitutional factors may account for maternal and infant characteristics. It is relevant to note that in our own earlier study of borderline mothers and their 2-month-olds (Crandell et al., 2003), the infants appeared to relate to their mothers much like control infants and without sign of unusual characteristics, and this despite evidence that the mothers were intrusively insensitive, until the stress of a still-face procedure was introduced. Although prima facie, the infants did not appear to be eliciting specific forms of maternal relatedness, further study is required to decide this issue. When taken together, the two studies suggest that infants 
of mothers with BPD develop characteristic patterns of relatedness that originate in the early months of life, and find new expression by 12 months of age.

The results of the study were revealing not only for infants' patterns of relatedness toward a stranger, but also their attachment relationships toward their mothers, and we are far from understanding the links between these partly separable facets of social development. The extensive and lively literature on the relations among stranger anxiety, temperament, and attachment is sufficient to discourage premature assumptions in this respect (see, e.g., Bradshaw, Goldsmith, \& Campos, 1987; Goldsmith \& Campos, 1990; Sroufe, 1985; SusmanStillman, Kalkoske, Egeland, \& Waldman, 1996; Thompson \& Lamb, 1982, 1983; Vaughn, Stevenson-Hinde, Waters, Kotsaftis, Lefever, Shouldice, Trudel, \& Belsky, 1992; Weber, Levitt, \& Clark, 1986). Given the intrapsychic and socially expressed characteristics of borderline psychopathology (for instance, as captured by the Adult Attachment Interview, e.g., Patrick et al., 1994; or the Personal Relatedness Profile, e.g., Hobson et al., 1998; or the Reflective-Self Function Scale, e.g., Fonagy et al., 1996), this condition appears to have special potential not only for elucidating the interaction among different kinds of maternal and infant risk factors for Disorganized attachment, but also for yielding insights into the connections between early forms of social relatedness and personal relationship.

It was with this in mind that for the present study, we adopted an "interpersonal" focus. In this regard, we conclude with two points, one methodological and one theoretical. The methodological point concerns the Modified Set Situation, which is in some ways novel and original (mainly attributable to Winnicott), and in others resembles the still-face challenge and previous tests of stranger anxiety. As Baron (1993) has emphasized, infants' responses to strang-

\section{References}

Ainsworth, M. D., Blehar, M., Waters, E., \& Wall, S. (1978). Patterns of attachment. Hillsdale, NJ: Erlbaum.

Ainsworth, M. D., \& Wittig, B. (1969). Attachment and exploratory behavior of one-year-olds in a strange ers are influenced by details of the setting in which the encounter occurs, and perhaps especially whether the meeting is controlled by the stranger (usually, by active approach) or the infant (where the adult maintains a distance and is responsive rather than intrusive). The Modified Set Situation has properties of each kind of encounter, and presents infants with a complex social challenge. It is plausible that our unfulfilled prediction of group differences in infants' willingness to hand the spatula to the stranger reflects a disparity between the ability to respond to a behavioral request on the one hand, and the capacity to negotiate more personal forms of involvement on the other. On a theoretical level, there is a point made by workers from very different theoretical positions (e.g., Bion, 1962; Shapiro, Fagen, Prigot, Carroll, \& Shalan, 1998): one needs to consider how human emotion regulation may implicate patterns not only of self-control but also interpersonal control (in the present case, control of, influence upon, and/or responsiveness to the mother and the stranger) and it would not be surprising if styles of interpersonal control regulation draw upon constitutional biases in sociability.

Finally, we need to consider what the study may suggest about the transgenerational transmission of psychopathology. There is growing evidence that Disorganized infant attachments prefigure socioemotional difficulties in later childhood and even adulthood (e.g., Carlson, 1998; Lyons-Ruth \& Jacobvitz, 1999; van IJzendoorn et al., 1999). Not only this, but in their relatedness toward a stranger in the Modified Set Situation, there were signs that all was not well for infants of mothers with borderline BPD. For the sake of these mothers and their infants, we need further research on the constitutional, relational, and psychodynamic aspects of this serious personality disorder, and on the developmental implications for the offspring of affected mothers. situation. In B. M. Foss (Ed.), Determinants of infant behavior IV (pp. 111-136). London: Methuen.

American Psychiatric Association. (1987). Diagnostic and statistical manual of mental disorders-Revised (3rd ed.). Washington, DC: Author. 
Baron, M. J. O. (1993). Fear, attachment and affiliation: The interaction of functional systems in 8- and 12month-old infants. Early Development and Parenting, 2, 121-130.

Barone, L. (2003). Developmental protective and risk factors in borderline personality disorder: A study using the Adult Attachment Interview. Attachment \& $\mathrm{Hu}$ man Development, 5, 64-77.

Bezirganian, S., Cohen, P., \& Brook, J. S. (1993). The impact of mother-child interaction on the development of borderline personality disorder. American Journal of Psychiatry, 150, 1836-1842.

Bion, W. R. (1962). A theory of thinking. International Journal of Psychoanalysis, 43, 306-310.

Bokhorst, C. L., Bakermans-Kranenburg, M. J., Fearon, R. M., van IJzendoorn, M. H., Fonagy, P., \& Schuengel, C. (2003). The importance of shared environment in mother-infant attachment security: A behavioral genetic study. Child Development, 74, 1769-1782.

Bowlby, J. (1969). Attachment and loss: Vol. 1. Attachment. New York: Basic Books.

Bradshaw, D. A., Goldsmith. H. A., \& Campos J. J. (1987). Attachment, temperament, and social referencing: Interrelationships among three domains of infant affective behavior. Infant Behavior and Development, 10, 223-231.

Brazelton, T. B., Koslowski, B., \& Main, M. (1974). The origins of reciprocity: The early mother-infant interaction. In M. Lewis \& L. A. Rosenblum (Eds.), The effect of infancy on its caregiver (pp. 49-77). New York: Wiley.

Bretherton, I., \& Ainsworth, M. D. S. (1974). Responses of one-year-olds to a stranger in a strange situation. In M. Lewis \& L. A. Rosenblum (Eds.), Origins of fear (pp. 131-164). New York: Wiley.

Bretherton, I., \& Munholland, K. A. (1999). Internal working models in attachment relationships: A construct revisited. In J. Cassidy \& P. R. Shaver (Eds.), Handbook of attachment: Theory, research and clinical applications (pp. 89-111). New York: Guilford Press.

Buss, A. H., \& Plomin, R. (1984). Temperament: Early developing personality traits. Hillsdale, NJ: Erlbaum.

Carlson, E. A. (1998). A prospective longitudinal study of attachment disorganization/disorientation. Child Development, 69, 1107-1128.

Carlson, V., Cicchetti, D., Barnett, D., \& Braunwald, K. (1989). Disorganized/disoriented attachment relationships in maltreated infants. Developmental Psychology, 25, 525-531.

Cohn, J. F., Campbell, S. B., Matias, R., \& Hopkins, J. (1990). Face-to-face interactions of postpartum depressed and nondepressed mother-infant pairs at 2 months. Developmental Psychology, 26, 15-23.

Cohn, J. F., Matias, R., Tronick, E. Z., Connell, D., \& Lyons-Ruth, K. (1986). Face-to-face interactions of depressed mothers and their infants. In E. Tronick \& T. Field (Eds), New directions for child development: Vol. 34. Maternal depression and infant disturbance (pp. 31-44). San Francisco, CA: Jossey-Bass.

Cohn, J. F., \& Tronick, E. (1989). Specificity of infants' response to mothers' affective behavior. American Academy of Child and Adolescent Psychiatry, 28, 242-248.

Crandell, L. E., Patrick, M. P. H., \& Hobson, R. P. (2003). "Still-face" interactions between mothers with borderline personality disorder and their 2-month-old infants. British Journal of Psychiatry, 183, 239-247.
Crockenberg, S. (1981). Infant irritability, mother responsiveness, and social support influences on the security of infant-mother attachment. Child Development, 52, 857-865.

DeMulder, E. K., \& Radke-Yarrow, M. (1991). Attachment with affectively ill and well mothers: Concurrent behavioral correlates. Development and Psychopathology, 3, 227-242.

De Wolff, M., \& van IJzendoorn, H. (1997). Sensitivity and attachment: A meta-analysis on parental antecedents of infant attachment. Child Development, 68, 571-591.

Field, T. M., Healy, B., Goldstein, S., \& Guthertz, M. (1990). Behavior-state matching and synchrony in mother-infant interactions in non-depressed versus depressed dyads. Developmental Psychology, 26, 7-14.

Field, T. M., Healy, B., Goldstein, S., Perry, S., Bendell, D., Schanberg, S., Zimmerman, E. A., \& Kuhn, C. (1988). Infants of depressed mothers show "depressed" behavior even with non-depressed adults. Child Development, 59, 1569-1579.

Field, T. M., Sandberg, D., Garcia, R., Vega-Lahr, N., Goldstein, S., \& Guy, L. (1985). Pregnancy problems, postpartum depression and early mother-infant interactions. Developmental Psychology, 21, 1152-1156.

Fonagy, P., Leigh, T., Steele, M., Steele, H., Kennedy, R., Mattoon, G., Target, M., \& Gerber, A. (1996). The relation of attachment status, psychiatric classification, and response to psychotherapy. Journal of Consulting and Clinical Psychology, 64, 22-31.

Fox, N. A., Kimmerly, N. L., \& Schafer, W. D. (1991). Attachment to mother/attachment to father. Child Development, 62, 210-225.

Garcia-Coll, C. T., Kagan, J., \& Reznick, J. S. (1984). Behavioral inhibition in young children. Child Development, 55, 1006-1019.

George, C., Kaplan, N., \& Main, M. (1985). The Adult Attachment Interview for Adults (2nd ed.). Unpublished manuscript, University of California at Berkeley.

Goldsmith, H. H., \& Campos, J. J. (1990). The structure of temperamental fear and pleasure in infants: A psychometric perspective. Child Development, 61, 1944-1964.

Greenberg, J. R., \& Mitchell, S. A. (1983). Object relations in psychoanalytic theory. Cambridge, MA: Harvard University Press.

Gunderson, J. G. (2001). Borderline personality disorder: A clinical guide. Washington, DC: American Psychiatric Publishing.

Guntrip, H. (1977). Personality structure and human interaction. London: Hogarth.

Gustafson, G. E., Green, J., \& West, M. J. (1979). The infant's changing role in mother-infant games: The growth of social skills. Infant Behavior and Development, 2, 301-308.

Hay, D. F., \& Murray, P. (1982). Giving and requesting: Social facilitation of infants' offers to adults. Infant Behavior and Development, 5, 301-310.

Herman, J., Perry, C., \& Van der Kolk, B. (1989). Childhood trauma in borderline personality disorder. American Journal of Psychiatry, 146, 490-495.

Hipwell, A. E., Goossens, F. A., Melhuish, E. C., \& Kumar, R. (2000). Severe maternal psychopathology and infant-mother attachment. Development and Psychopathology, 12, 157-175.

Hobson, R. P. (1997). Psychoanalysis and infancy. In G. Bremner, G. Butterworth, \& A. Slater (Eds.), Infant development: Recent advances (pp. 275-290). Hove: Psychology Press. 
Hobson R. P. (2002). The cradle of thought. London: Macmillan.

Hobson, R. P., Patrick, M. P. H., Crandell, L. E., GarciaPerez, R. M., \& Lee, A. (2004). Maternal sensitivity and infant triadic communication. Journal of Child Psychology and Psychiatry, 45, 470-480.

Hobson, R. P., Patrick, M. P. H., \& Valentine, J. D. (1998). Objectivity in psychoanalytic judgements. British Journal of Psychiatry, 173, 172-177.

Jackson, J. (1996). An experimental investigation of Winnicott's set situation: A study of South African white, black and institutionalized infants aged 7 to 9 months old. Journal of Child Psychotherapy, 22, 343-361.

Kernberg, O. F. (1976). Object relations theory and clinical psychoanalysis. Northvale, NJ: Aronson.

Lakatos, K., Nemoda, Z., Toth, I., Ronai, Z., Ney, K., Sasvari-Szekely, M., \& Gervai, J. (2002). Further evidence for the role of the dopamine D4 receptor (DRD4) gene in attachment disorganization: Interaction of the exon III 48 -bp repeat and the $-521 \mathrm{C} / \mathrm{T}$ promoter polymorphisms. Molecular Psychiatry, 7 , $27-31$.

Landis, J. R., \& Koch, G. G. (1977). The measurement of observer agreement for categorical data. Biometrics, 33, 159-174.

Lyons-Ruth, K., Bronfman, E., \& Atwood, G. (1999). A relational diathesis model of hostile-helpless states of mind. Expressions in mother-infant interaction. In J. Solomon \& C. George (Eds.), Attachment disorganization (pp. 33-70). New York: Guilford Press.

Lyons-Ruth, K., Bronfman, E., \& Parsons, E. (1999). Maternal frightened, frightening, or atypical behavior and disorganized infant attachment patterns. Monographs of the Society for Research in Child Development, 64(3, Serial No. 258), 67-96.

Lyons-Ruth, K., Connell, D. B., Zoll, D., \& Stahl, J. (1987). Infants at social risk: Relations among infant maltreatment, maternal behavior, and infant attachment behavior. Developmental Psychology, 23, 223-232.

Lyons-Ruth, K., \& Jacobvitz, D. (1999). Attachment disorganization: Unresolved loss, relational violence, and lapses in behavioral and attentional strategies. In J. Cassidy \& P. R. Shaver (Eds.), Handbook of attachment: Theory, research, and clinical applications (pp. 520-554). New York: Guilford Press.

Lyons-Ruth, K., Repacholi, B., McLeod, S., \& Silva, E. (1991). Disorganized attachment behavior in infancy: Short-term stability, maternal and infant correlates, and risk-related subtypes. Development and Psychopathology, 3, 377-396.

Main, M., \& Hesse, E. (1990). Parents' unresolved traumatic experiences are related to infant disorganized attachment status: Is frightened and/or frightening parental behavior the linking mechanism? In M. T. Greenberg, D. Cicchetti, \& E. M. Cummings (Eds.), Attachment in the preschool years: Theory, research, and intervention (pp. 161-182). Chicago: University of Chicago Press.

Main, M., \& Solomon, J. (1986). Discovery of a new, insecure-disorganized/disoriented attachment pattern. In T. B. Brazelton \& M. W. Yogman (Eds.), Affective development in infancy (pp. 95-124). Norwood, NJ: Ablex.

Main, M., \& Solomon, J. (1990). Procedures for identifying infants as disorganized/disoriented during the Ainsworth strange situation. In M. T. Greenberg, D. Cicchetti, \& E. M. Cummings (Eds.), Attachment in the preschool years: Theory, research, and interven- tion (pp. 121-160). Chicago: University of Chicago Press.

Main, M., \& Weston, D. R. (1981). The quality of the toddler's relationship to mother and to father: Related to conflict behavior and the readiness to establish new relationships. Child Development, 52, 932-940.

Manassis, K., Bradley, S., Goldberg, S., Hood, J., \& Swinson, R. P. (1994). Attachment in mothers with anxiety disorder and their children. Journal of the American Academy of Child and Adolescent Psychiatry, 33, 1106-1113.

Melnick, S. M., Patrick, M. P. H., Lyons-Ruth, K., \& Hobson, R. P. (2003). Disorganized (hostile/helpless) attachments in mothers with psychopathology. Poster presented at the Biennial Meeting of the Society for Research in Child Development, Tampa, FL.

Murray, L., \& Cooper, P. J. (1997). Postpartum depression and child development. New York: Guilford Press.

Murray, L., Fiori-Cowley, A., Hooper, R., \& Cooper, P. (1996). The impact of postnatal depression and associated adversity on early mother-infant interactions and later outcome. Child Development, 67, 2512-2526.

O'Connor, M. J., Sigman, M., \& Brill, N. (1987). Disorganization of attachment in relation to maternal alcohol consumption. Journal of Consulting and Clinical Psychology, 55, 831-836.

O'Connor, T. G., \& Croft, C. M. (2001). A twin study of attachment in preschool children. Child Development, $72,1501-1511$.

Ogata, S., Silk, K., Goodrich, S., Lohr, N., Westen, D., \& Hill, E. (1990). Childhood sexual and physical abuse in borderline patients. American Journal of Psychiatry, 147, 1008-1013.

Patrick, M., Hobson, R. P., Castle, D., Howard, R., \& Maughan, B. (1994). Personality disorder and the mental representation of early social experience. Development and Psychopathology, 6, 375-388.

Posner, M. I., Rothbart, M. K., Vizueta, N., Thomas, K. M., Levy, K. N., Fossella, J., Silbersweig, D., Stern, E., Clarkin, J., \& Kernberg, O. (2003). An approach to the psychobiology of personality disorders. Development and Psychopathology, 15, 1093-1106.

Reinecke, M. A., \& Fogel, A. (1994). The development of referential offering in the first year. Early Development and Parenting, 3, 181-186.

Rothbart, M. K., \& Derryberry, D. (1981). Development of individual differences in temperament. In M. E. Lamb \& A. L. Brown (Eds.), Advances in developmental psychology (Vol. 1, pp. 37-86). Hillsdale, NJ: Erlbaum.

Rodning, C., Beckwith, L., \& Howard, J. (1991). Quality of attachment and home environments in children prenatally exposed to PCP and cocaine. Development and Psychopathology, 3, 351-366.

Sandler, J. (Ed.). (1988). Projection, identification, projective identification. London: Karnac.

Schneider Rosen, K., \& Rothbaum, F. (1993). Quality of parental caregiving and security of attachment. Developmental Psychology, 29, 358-367.

Schuengel, C., Bakermans-Kranenburg, M. J., \& van IJzendoorn, M. H. (1999). Frightening maternal behavior linking unresolved loss and disorganized infant attachment. Journal of Consulting and Clinical Psychology, 67, 54-63.

Shapiro, B., Fagen, J., Prigot, J., Carroll, M., \& Shalan, J. (1998). Infants' emotional and regulatory behaviors in response to violations of expectancies. Infant Behavior and Development, 21, 299-313. 
Skodol, A. E., Siever, L. J., Livesley, W. J., Gunderson, J. G., Pfohl, B., \& Widiger, T. A. (2002). The borderline diagnosis: II. Biology, genetics, and clinical course. Biological Psychiatry, 51, 951-963.

Spangler, G., \& Grossmann, K. (1999). Individual and physiological correlates of attachment disorganization in the infancy. In J. Solomon \& C. George (Eds.), Attachment Disorganization (pp. 95-124). New York: Guilford Press.

Spitzer, R. L., Williams, J. B. W., Gibbon, M., \& First, M. B. (1990). Structured clinical interview for DSMIII-R-Personality disorders (SCID-II Version 1.0); and non-patient edition (SCID-NP, Version 1.0). Washington, DC: American Psychiatric Association.

Sroufe, L. A. (1977). Wariness of strangers and the study of infant development. Child Development, 48, 731-746.

Sroufe, L. A. (1985). Attachment classification from the perspective of infant-caregiver relationships and infant temperament. Child Development, 56, 1-14.

Stein, A., Woolley, H., Cooper, S. D., \& Fairburn, C. G. (1994). An observational study of mothers with eating disorders and their infants. Journal of Child Psychology and Psychiatry, 35, 733-48.

Stein, A., Woolley, H., \& McPherson, K. (1999). Conflict between mothers with eating disorders and their infants during mealtimes. British Journal of Psychiatry, $175,455-461$.

Stevenson, M. B., \& Lamb, M. E. (1979). Effects of infant sociability and the caretaking environment on infant cognitive performance. Child Development, 50 , 340-349.

Stern, D. N. (1985). The interpersonal world of the infant. New York: Basic Books.

Susman-Stillman, A., Kalkoske, M., Egeland, B., \& Waldman, I. (1996). Infant temperament and maternal sensitivity as predictors of attachment security. Infant Behavior and Development, 19, 33-47.

Teti, D. M., Gelfand, D. M., Messinger, D. S., \& Isabella, R. (1995). Maternal depression and the quality of early attachment: An examination of infants, preschoolers, and their mothers. Developmental Psychology, 34, 361-376.
Thompson, R. A., \& Lamb, M. E. (1982). Stranger sociability and its relationships to temperament and social experience during the second year. Infant Behavior and Development, 5, 277-287.

Thompson, R. A., and Lamb, M. E. (1983). Security of attachment and stranger sociability in infancy. Child Development, 19, 184-191.

Trevarthen, C., \& Hubley, P. (1978). Secondary intersubjectivity: Confidence, confiding and acts of meaning in the first year. In A. Lock (Ed.), Action, gesture and symbol: The emergence of language (pp. 183-229). London: Academic Press.

Tronick, E. Z., \& Cohn, J. F. (1989). Infant-mother faceto-face interaction: Age and gender differences in coordination and the occurrence of miscoordination. Child Development, 60, 85-92.

van IJzendoorn, M. H. (1995). Adult attachment representations, parental responsiveness, and infant attachment: A meta-analysis on the predictive validity of the Adult Attachment Interview. Psychological Bulletin, 117, 387-403.

van IJzendoorn, M. H., Schuengel, C., \& BakermansKranenburg, M. J. (1999). Disorganized attachment in early childhood: Meta-analysis of precursors, concomitants, and sequelae. Development and Psychopathology, 11, 225-249.

Vaughn, B. E., Stevenson-Hinde, J., Waters, E., Kotsaftis, A., Lefever, G. B., Shouldice, A., Trudel, M., \& Belsky, J. (1992). Attachment security and temperament in infancy and early childhood: Some conceptual clarifications. Developmental Psychology, 28, 463-473.

Weaver, T. L., \& Clum, G. A. (1993). Early family environments and traumatic experiences associated with borderline personality disorder. Journal of Consulting and Clinical Psychology, 61, 1068-1075.

Weber, R. A., Levitt, M. J., \& Clark, M. C. (1986). Individual variation in attachment security and strange situation behavior: The role of maternal and infant temperament. Child Development, 57, 56-65.

Winnicott, D. W. (1941). The observation of infants in a set situation. International Journal of Psychoanalysis, 22, 229-249. 